\title{
perifèria
}

Número 20 (2), diciembre 2015

revistes.uab.cat/periferia

\section{Reconfiguración del género en las performances clásicas. Androginia actoral.}

\author{
Miren Urquijo Arregui - UPV/EHU. ${ }^{1}$
}

DOI: http://dx.doi.org/10.5565/rev/periferia.486

\section{Resumen}

El género, producto del entorno social y factor decisivo en la comunicación, habla de nuestras identidades y proyecta nuestras imágenes codificadas como masculinas o femeninas. Las técnicas cotidianas de comportamiento corporal y los códigos vestimentarios regulan los roles de género, pero sirven asimismo para jugar con ellos y subvertirlos. Este artículo reflexiona sobre cómo la androginia, arquetipo de la reunión de lo masculino y lo femenino, es escenificada en el teatro Kabuki, el teatro Renacentista ingles y el teatro del Siglo de Oro español, de manera que podemos hablar de esos actores y actrices que representan al otro sexo como un "tercer sexo". Y así, transgreden simbólicamente la creencia de que el comportamiento de un individuo está biológicamente programado. Al fin, en el cuerpo, -ficción social-, se abren múltiples posibilidades de reconfiguración del imaginario cultural genérico.

Palabras clave: performance, género, androginia, antropología.

\begin{abstract}
Gender, product of the social environment and decisive factor in the communication, speaks of our identities and projects our images encoded as male or female. Everyday techniques for body behavior and dress codes regulate gender roles, but are also used to play with them and subvert them. This article reflects on how the androgyny, archetype of the meeting of the masculine and the feminine, is staged in Kabuki Theatre, English Renaissance Theatre and the Theatre of the Spanish Golden Age, so we can talk about the actors and actresses who represent the opposite sex as a "third sex". And so, they transgress symbolically the believe that behavior is biologically and sexually programmed. Concluding, within the social fiction of the body there are multiple possibilities of reconfiguration of the generic cultural imaginary.
\end{abstract}

Key words: performance, gender, androgynous, anthropology

\footnotetext{
${ }^{1}$ Enviar correspondencia a: Miren Urquijo, miren.urquijo@ehu.es
} 


\section{perifèria}

Número 20 (2), diciembre 2015

revistes.uab.cat/periferia

All the world's a stage, And all the men and women merely players.

(As You Like It, 139-140)

\section{Introducción}

El género es un producto del entorno social y un factor decisivo en la comunicación. La masculinidad o la feminidad son códigos que nos sirven para hablar de nuestras identidades, es decir, para construir imágenes de nosotros mismos y proyectarlas a través de nuestras apariencias (G. Cortés, 1997: 82-83).

Tal y como afirma José Miguel G. Cortes, si toda expresión corporal está relacionada con la normalidad y determinada por la cultura, si los condicionamientos sociales y las experiencias personales constituyen un entramado de significados que sujetan al cuerpo (1997:79), si el cuerpo no es exclusivamente un ente natural sino, también, una construcción social que dota a cada género de un código claro y conciso que plantea como un hombre (masculino) o una mujer (femenina) debe comportarse y actuar (1997: 81-82), podemos decir que toda persona desarrolla, en función de esto, sus propias técnicas cotidianas de comportamiento. El antropólogo Marcel Mauss habló por primera vez en 1934 de las "técnicas del cuerpo", es decir, de las formas en que las personas, en las distintas sociedades, utilizan, de acuerdo con la tradición, su propio cuerpo. En su texto, Mauss enumera una gran diversidad de técnicas corporales que le son enseñadas al hombre según su cultura a lo largo de su biografía, especificando la variedad existente en técnicas de nacimiento, técnicas para sujetar los niños, técnicas para dormir, técnicas de reposo, de comer, de reproducción, etc. (Barba y Savarese, 1990: 300-305).

Sabemos que la regulación de los géneros se ha llevado a cabo, también, a través de códigos vestimentarios. La ropa es, quizás, el mayor o más importante símbolo del género que permite a las otras personas identificar inmediatamente el rol de género individual (G. Cortés, 1997: 83). Una convincente imagen masculina 


\section{perifèria}

\section{Número 20 (2), diciembre 2015 \\ revistes.uab.cat/periferia}

permite a las mujeres acceder a las prerrogativas del status masculino. En ciertas comunidades de los Balcanes, podemos aún ver que mujeres biológicas viven sus vidas, o la mayor parte de sus vidas, "as social men" (Herdt, 1993: 242) y así, podemos "Speak of the Balkan "socialmen" as a third gender "(idem 246). Con ello saltan en añicos los sistemas binarios de oposición, se hacen múltiples las representaciones y se desnaturaliza la rigidez de géneros. Se crea una brecha entre el sexo biológico y la identidad asignada al elegir ser otro/a distinto/a del que se ha nacido, se extiende el principio de incertidumbre, se abolen los límites y se vislumbra una pérdida de cualquier principio referencial (G. Cortés 1997:84-85).

En las leyendas, folklore, cuentos de todos los pueblos y tiempos encontramos muchachas que se disfrazan de muchachos para poder hacer aquello que las costumbres negaban a su sexo. Por ejemplo, en Diálogos de cortesanas de Aretino (1492-1557) se aconseja a las muchachas disfrazarse de muchacho como medio más eficaz para despertar la pasión (Kot 1989: 313) o en Orlando Furioso de Ariosto (1474-1533) Bradamanta, disfrazada de guerrero, provoca los ardientes deseos de una infanta española. En esa época el disfraz tiene aún un fondo metafísico que provienen de su pasado litúrgico, siendo no sólo el intento de una erótica libre de las limitaciones del cuerpo, sino el sueño de un amor libre de las limitaciones del sexo (Kot 1989: 324).

El correlativo metafórico del disfraz es la androginia; un arquetipo, una noción y una representación de la unión del elemento masculino con el femenino (Kot 1989: 316). En todas las teogonías de la creación del mundo aparecen dioses andróginos. Luego, durante el renacimiento, se produjo un resurgimiento en el arte, en la filosofía, en la mística religiosa de esos mitos antiguos y Dionisio, Diana, etc., se convirtieron en mitos andróginos vivos y activos.

La pintura renacentista italiana acusa esta influencia. Verrocchio fue el primero en crear el modelo de muchacho-muchacha (establecido en Eros Socráticus de la metafísica platónica) para la pintura de los ángeles. Con Botticelli las muchachas se vuelven parecidas a los chicos. Los tres Davides florentinos: el de Donatello, el de Verrocchio y el de Miguel Ángel manifiestan las transformaciones 


\section{perifèria}

\section{Número 20 (2), diciembre 2015}

revistes.uab.cat/periferia

del desnudo masculino y el canon de efebo. Son cada vez más menudos, más nerviosos, más femeninos (Kot 1989: 298-302).

El mito andrógino es, entre otras cosas, una evocación del paraíso perdido, donde coexisten todas las contradicciones al fin coincidentes (Kot 1989: 343). "Nicolás de Cusa (1401-1464) consideraba el término "coincidencia oppositorum" como la menos imperfecta definición de la naturaleza divina. El hombre fue creado a imagen y semejanza de Dios, pero no fueron creados a imagen y semejanza de Dios ni el varón ni la hembra sino la andrógina. De la andrógina toma su origen el género humano" (Kot 1989: 344).

Estos mitos fecundaban las imaginaciones. Su finalidad principal, en la Italia de los Médicis, era proporcionar un principio metafísico y moral, autorizado por el pasado, para la unificación de la política, del arte y de las costumbres en la cultura en vías de creación (Kot, 1989: 346).

Cualquier actor y actriz, al jugar con otras identidades, busca en su interpretación un sistema equivalente al formado por las técnicas cotidianas del contexto y personaje representado. No obstante, es un instrumento determinado culturalmente, tanto en su vida cotidiana como en su sistema de representación. Sus técnicas cotidianas de comportamiento dependen de su cultura, de su condición social, de su género, etc. Así, en situación de representación, emplea técnicas extra-cotidianas, codificadas para transformar los procesos fisiológicos y condicionamiento corporales habituales y así, reproducir la realidad en un sistema equivalente con una cualidad estética añadida. Por ello, podríamos hablar también de los actores/actrices que representan al otro sexo "as a third gender".

El siguiente apartado me centraré en algunos conceptos desarrollados en la antropología teatral de Eugenio Barba y Nicola Savarese al estudiar el comportamiento fisiológico y sociocultural del ser humano en situación de representación (Barba y Savarese, 1990), y específicamente en aquellos que se refieren a la actuación de actores representando mujeres y actrices representando hombres. Posteriormente, los apartados segundo y tercero recogerán este hecho en el Kabuki, el teatro Renacentista inglés y el teatro del Siglo de Oro español. 


\section{perifèria}

Número 20 (2), diciembre 2015

revistes.uab.cat/periferia

\section{Cuerpo ficticio/Cuerpo imaginario}

Eugenio Barba y Nicola Savarese (1990) en su texto El arte secreto del actor señalan cuestiones vinculadas al comportamiento actoral en representaciones del otro género en los capítulos dedicados a la dilatación, energía, equilibrio, preexpresividad y restauración del comportamiento y así titulados. Paso a realizar una síntesis de sus principales conceptos:

Primero.- El actor está constituido por dos diferentes niveles de organización. Llamamos nivel expresivo al nivel en el que el actor construye su estilo interpretativo, poético, estético, dramatúrgico, etc. Al nivel base que es común a todos los actores de cualquier cultura lo definimos como nivel preexpresivo. En él el actor construye su propia presencia en escena, independientemente y antes de sus finalidades y resultados expresivos (en sentido lógico, pues en escena ambos niveles actúan simultáneamente).

Segundo.- El teatro occidental, por lo menos el teatro occidental moderno, se basa en la identificación entre el cuerpo individual cotidiano y el cuerpo imaginario del personaje. Se cree, o al menos se ha creído, que sólo existen estos dos niveles. En cambio, en la mayor parte de las formas tradicionales de teatro oriental se descubre fácilmente un nivel intermedio entre el cuerpo cotidiano del actor y el cuerpo imaginario, por decirlo así, del personaje. Al cuerpo de ese nivel lo llamamos cuerpo ficticio, pues finge una especie de transformación del cuerpo a nivel pre-expresivo, es decir, construye una presencia lista a representar, preparada ante la posibilidad de poder actuar, un-cuerpo-en-vida que dilata la presencia del actor y la percepción del espectador.

Tercero.- A nivel expresivo, el cuerpo cotidiano del actor desarrolla técnicas de comportamiento determinadas por su cultura, su condición social, etc. Las 


\section{perifèria}

Número 20 (2), diciembre 2015

revistes.uab.cat/periferia

podemos denominar técnicas cotidianas. En situación de representación, pese a ello, el cuerpo del actor no respeta sus condicionamientos habituales y transforma su técnica cotidiana en técnica extracotidiana. Mediante ella, codifica un equivalente de los procesos fisiológicos humanos con una cualidad estética añadida. Es decir, el actor, mediante la técnica extracotidiana, que es lo contrario a la imitación, reproduce la realidad a través de un sistema equivalente por el que sus acciones conservan toda la potencia y energía de la realidad.

Cuarto.- Este sistema equivalente, a nivel expresivo, es diferente si el actor construye el sentido de su representación mediante una técnica extracotidiana inculturada o una técnica extracotidiana aculturada. La aculturada generalmente es impuesta por una tradición muy codificada (como por ejemplo la oriental). Esta técnica distorsiona la apariencia inculturada cotidiana y estiliza o artificializa el comportamiento del actuante, ya que establece una diferencia expresiva con las técnicas de comportamiento utilizadas en la vida cotidiana. En contraposición, la técnica extracotidiana inculturada persigue reproducir sin distorsión la apariencia inculturada cotidiana. Corresponde al teatro occidental moderno y su mayor aporte metodológico lo han dado Stanislavsky y Brech; Stanislavsky al vivificar la conducta inculturada mediante el "si mágico" y Brech al hacer modelar al actor su comportamiento cotidiano en uno "extracotidiano con subtextos sociales" a través del distanciamiento o el gestus social.

Quinto.- Con todo, y a pesar de producir a nivel expresivo resultados diferentes, tanto la técnica extracotidiana inculturada como la aculturada activan el nivel pre-expresivo del actor, es decir, construyen su cuerpo ficticio. ¿Cómo? Mediante un trabajo que simultáneamente y en recíproca interdependencia pone en acción tres procesos: el proceso de dilatación, el proceso de omisión y el proceso de consecución del "ritmo justo". Expongo brevemente cada uno: 


\section{perifèria}

Número 20 (2), diciembre 2015

revistes.uab.cat/periferia

1.- Proceso de Dilatación: Este trabajo se realiza en base a tres líneas de acción

1.1.- Alteración del equilibrio cotidiano y búsqueda de un equilibrio precario o "de lujo": Ley de la Diagonal, Ley de los tres Arcos, Ley de la Asimetría, reducir la base de apoyo, inclinación del escenario.

1,2.- Dinámica de las oposiciones: crear oposiciones, tensiones de fuerzas opuestas, diferencias de potencial que hacen al cuerpo vivo, fuertemente presente incluso en movimientos lentos 0 inmovilidad aparente.

1,3.- Uso de la incoherencia coherente: peripecia, desorientación y precisión para conseguir un cuerpo-mente dilatado

2.- Proceso de Omisión: Reconstruir el sistema equivalente procediendo por eliminación de todo lo superfluo; fragmentación y reconstrucción que esencializa. También, capacidad de retener la energía en el espacio y en el tiempo

3.- Proceso con el Ritmo: incidir en el tiempo, esculpiendo el tiempo en ritmo, dilatando y contrastando sus acciones mediante una respiración, un fluir, una alternancia continua que protege el perfil individual de cada acción.

Resumiendo: el actor en situación de representación produce un cuerpo ficticio y un comportamiento artificial, extra-cotidiano. En la ficción del teatro es un cuerpo-en-vida. Activando el nivel pre-expresivo, dilata su presencia y, en consecuencia, dilata la percepción del espectador. Según sea su tradición teatral, utiliza para ello procesos mentales, "si" mágicos, subtextos personales; o imagina su cuerpo en el centro de una red de tensiones y resistencias físicas irreales pero eficaces; o usa una técnica extra-cotidiana del cuerpo y de la mente que tiene origen en una alteración del equilibrio y de las posturas de base, o en el juego de tensiones contrapuestas que dilatan la dinámica del cuerpo, etc. 


\section{perifèria}

Número 20 (2), diciembre 2015

\section{revistes.uab.cat/periferia}

Mediante este proceso pre-expresivo, el cuerpo es re-puesto en forma, reconstruido para la ficción teatral. Pareciera, en el nivel visible, que trabaja sobre el cuerpo y la voz. Con ello, en realidad, trabaja sobre algo invisible, la energía, concepto que cuando se aplica al actor se asocia al ímpetu externo, al exceso de actividad muscular y nerviosa, pero que indica también una temperatura-intensidad personal que este puede individualizar, despertar y modelar (Barba y Savarese, 1990: 90).

Este cuerpo ficticio, este "cuerpo de arte", -y por lo tanto "no natural"- no es de por sí ni hombre ni mujer. En el nivel expresivo, en el de los resultados del espectáculo, la presencia del actor o de la actriz es figura escénica, personaje y caracterización masculina o femenina. Cuando domina también en el terreno preexpresivo, es innecesaria y dañosa. A nivel pre-expresivo, importa poco el sexo del actor. Sería arbitrario connotar sexualmente la amplitud de órbita entre cuyos polos están una energía vigorosa animus y una energía suave anima (Barba y Savarese, 1990: 91).

En el periodo de aprendizaje, la diferenciación individual debe pasar por la negación de la diferenciación de los sexos, por dilatar el campo de las complementaridades: esto se ve cuando en Occidente, en el mimo o la danza moderna, el entrenamiento -el trabajo sobre el nivel pre-expresivo- no tiene en cuenta lo masculino y lo femenino; o cuando en Oriente el actor representa indiferentemente roles masculinos y femeninos.

A propósito de esto, los balineses hablan de un continuo enlace de manis y keras, al igual que los hindúes de lasya y tandava. Son términos que no se refieren ni a mujeres ni a hombres, ni a cualidades femeninas o masculinas, sino a delicadeza y vigor como sabores de la energía. Por ello, en la mayor parte de Asia, actores y bailarines interpretan los personajes no tanto en base a la identidad del sexo sino como modelaje de la energía en una dirección fuerte o delicada mediante un codificado trabajo físico y mental (Barba y Savarese, 1990: 94).

En la tradición hindú, el nivel de energía se trabaja en el interior de una polaridad energética y no en el de la coincidencia entre personajes y sexo del actorbailarín: los estilos de la danza hindú están divididos en dos grandes categorías, 


\section{perifèria}

Número 20 (2), diciembre 2015

revistes.uab.cat/periferia

lasya (delicados) y tandava (vigorosos) en base a la manera en como son ejecutados los movimientos y no en base al sexo del ejecutor.

Actores representando mujeres y actrices representando varones son habituales en todas las tradiciones teatrales. Por acotar este estudio, se selecciona el teatro renacentista inglés, el teatro oriental y el teatro del Siglo de Oro español.

\section{El actor de mujeres}

Kabuki

La antigua y estable tradición japonesa de intérpretes masculinos para papeles femeninos -que se inventa por análogos motivos también en otros teatros de Asia como la Opera de Pekin o el Kathakali- muestra también cómo es posible hacer depender la interpretación no del sexo del actor sino más bien de su manera de modelar la energía. En un principio, hacia la mitad del S XVI, el Kabuki era representado sólo por actrices pero después su exhibición se volvió demasiado licenciosa; el gobierno de Shogun, por motivo de moral social, prohibió a las mujeres representar en público y decretó que los papeles femeninos del Kabuki fuesen sostenidos solamente por hombres. Tales actores fueron Ilamados onnagata. En virtud de este decreto, y más bien gracias a él, los onnagatas pudieron desarrollar una serie de técnicas refinadas y elaboradas para acercarse a la interpretación de la mujer, alcanzando vértices de perfección tales que todavía hoy la fascinación del Kabuki es en gran parte debido a su arte (Barba y Savarese 1990: 90).

José Miguel G. Cortés (1997) en "El rostro velado" nos da otra lectura de la figura del Onnagata, diciendo, entre otras cosas: "Onnagata es el término utilizado como personificación de lo femenino, de manera simbólica, lejos de las contingencias cotidianas de las mujeres. El rol del Onnagata tenía como función construir y representar el ideal simbólico del comportamiento de la mujer y la imagen del misterio de la metamorfosis y la androginia" (G.Cortés, 1997:33). En esta lectura, aunque nos habla de técnica aculturada, al contarnos que tanto su apariencia física como sus gestos y actitudes están netamente delimitados y codificados, olvida que tal es el estilo interpretativo Kabukhi o Noh, tanto para 


\section{perifèria}

Número 20 (2), diciembre 2015

revistes.uab.cat/periferia

personajes masculinos como femeninos y, quizás por ello, concluye: "Abstracción sublime e ideal de la mujer que tan sólo puede ser representada por hombres, (normalmente casados y heterosexuales) que se sienten más mujeres que las verdaderas mujeres". Sin embargo, aporta un dato más: "El Onnagata debe vivir como mujer en su vida normal; debe comer y comportarse según los códigos, jamás abandonar la cortesía de la esposa ni la seducción de la amante; jamás olvidar la ficción de su sexo, debe hacer del otro sexo su claustro, claustro que erige en destino su identidad femenina, identidad de arte" (Banu, G., L'Acteur que ne revient pas Paris, Gallimard, 1996: 53 en G. Cortés, 1997). Con lo que, siguiendo la terminología anterior, podemos decir que el Onnagata debe adoptar las técnicas cotidianas de la mujer para extracotidianamente, y siguiendo la tradición aculturada de su estilo teatral, representarla. Si esto es siempre así, supone fusión entre sueño y realidad, teatro y vida cotidiana, confusión y superación de las fronteras físicas y las actitudes de género más allá de las tablas del escenario; algo más que se desvestirse de la máscara de su sexo "para dejar vislumbrar un temperamento dulce o vigoroso, independiente de los esquemas a los que un hombre o una mujer deben conformar en una cultura determinada" (Barba y Sabarese, 1990).

\section{Shakespeare}

El actor, en la Europa del S. XVII (salvo en España e Italia) debía representar también los papeles femeninos, ya que las mujeres no podían interpretar por problemas de carácter moral. La ley expresamente lo prohibía. En Inglaterra, en concreto, aunque las damas de la corte participaban en las mascaradas, no llegaron a los teatros comerciales hasta las últimas décadas del S. XVIII (Bregazzi 1999: 63). Así, los papeles femeninos eran interpretados por jóvenes de 11 a 13/14 años, o hasta que les cambiaba la voz, que desde los 7-8 años habían sido sometidos a un sistema de rigurosa preparación (Bregazzi 1999: $31)$. 


\section{perifèria}

Número 20 (2), diciembre 2015

revistes.uab.cat/periferia

Desconocemos cómo era la técnica interpretativa en ese teatro, pues no nos ha llegado ningún manual gestual o de dicción. Si nos atenemos al discurso de Hamlet aconsejando a sus actores contratados, podemos deducir que los actores que representaban a Julieta, Lady Macbeth, etc. buscaban en su interpretación un sistema físico y emocional equivalente al formado por las técnicas cotidianas de las mujeres en esa época.

Como resultado, los actores, en cierta forma, transgredían, en una travesía simbólica a través de los géneros, la creencia de que el comportamiento de un individuo está biológicamente programado y, por ello, asociado a un género al que no puede dejar de pertenecer.

Pero no caigamos en la tentación de interpretarles desde nuestras concepciones, haciéndoles asumir intencionalidades que no existían en aquella época. Porque, por una parte, Thomas Laqueur nos dice que es a finales del S XVIII cuando se crea el concepto moderno de sexo: "el sexo sustituyó a lo que podríamos llamar género como categoría fundacional básica" (Laqueur, 1990: 265-266). "Durante buena parte del S XVII, ser hombre o mujer era ostentar un rango social, asumir un rol cultural, y no pertenecer orgánicamente a uno y otro de los sexos. El sexo era todavía una categoría sociológica y no ontológica" (Laqueur 1990: 246).

Además, las tensiones a las que estaba sujeto el sistema de género no eran exactamente las contemporáneas. En las primeras décadas del $\mathrm{S}$ XVII se produjeron una serie de cambios en el tejido social y sobre todo en los comportamientos de la mujer (travestismo, ir de copas juntas, tener abiertamente amantes, dirigir los negocios de sus maridos mejor que ellos, etc.), que alcanzaron gran éxito entre la población femenina de Londres y otras ciudades. El rey Jacobo I instó a todos los obispos para que pronunciasen homilías en su contra y es más, entre 1560 y 1640 se produjo el mayor número conocido de juicios contra mujeres por brujerías o por deslenguadas, en un intento de controlar su comportamiento desde la "justicia" (Bregazzi, 1999: 59). Semejante disparidad entre la legislación y lo que realmente estaban haciendo las mujeres, encaja perfectamente en el contexto general de disparidades, incongruencias y contradicciones del periodo en cuestión. Era una época en la que, dentro de una situación de quiebra de creencias 


\section{perifèria}

\section{Número 20 (2), diciembre 2015}

revistes.uab.cat/periferia

hasta entonces consideradas inmutables, de desmoronamiento del sistema social y político, de controversia religiosa, - en definitiva, ethos de inseguridad -, surgió un nuevo concepto de hombre en tanto que criatura de ilimitadas posibilidades, se produjo una mayor profundidad en el estudio del ser humano como sujeto $y$, en especial, de la mujer y su situación: elección libre de compañero, libertad sexual, derecho a la autonomía económica, su relación con el poder político, los obsoletos códigos de comportamiento femenino, etc. (Bregazzi, 1999: 28).

El teatro renacentista inglés articuló prácticamente todas las grandes polémicas de su tiempo. Era un foro, de gran éxito, en el que el espectador podía observar y escuchar actitudes polémicas, críticas al sistema, desafíos a los códigos de comportamiento, etc. Uno de los grandes temas que desarrolló fue el de las fronteras de la identidad, las diferentes identidades que confiere la sociedad, lo mutable de la identidad humana, la precariedad y mutabilidad de todo lo humano, de todas las estructuras sociales y de todas las identidades (Bregazzi 1999: 92-98). Los recursos teatrales, textuales y dramatúrgicos para tratar este tema eran muchos. Entre ellos destacaremos el disfraz, ya que la vestimenta era un signo externo de clase, codificado por las Laws of Apparel o Sumptuary Laws (Leyes de Vestimenta, aprobadas en 1597), las cuales prohibiendo, por ejemplo, el uso de ciertas telas a los burgueses y otorgando su uso exclusivo a la aristocracia, intentaban mantener las barreras de clase claramente visibles (Bregazzi, 1999).

Este clasista código vestimentario es subvertido y puesto en cuestión en muchas obras del teatro renacentista inglés, pero vamos a ocuparnos especialmente del disfraz que sirve para facilitar la confusión de géneros además de para poner de relieve la inestabilidad de la identidad.

Personajes femeninos disfrazados de masculinos eran habituales en el teatro de la época, pero en la escena isabelina tiene un matiz particular. Una muchacha se disfraza de muchacho, sin embargo antes un muchacho se había disfrazado de muchacha al ser los papeles femeninos desempeñados por los actores jóvenes. Era una especie de limitación. Se ve bien en Macbeth o en Antonio y Cleopatra que Shakespeare se debatía contra esas limitaciones en la interpretación. Pero dos veces al menos Shakespeare hizo de esa limitación el tema y, al mismo 


\section{perifèria}

\section{Número 20 (2), diciembre 2015 \\ revistes.uab.cat/periferia}

tiempo, el instrumento teatral de una comedia. Fue en Noche de Reyes (escrita en 1.602) y en Como gustéis (escrita en 1.600) (Kot 1989: 307). En sus escenas amorosas existe una total correlación y una compenetración mutua de la forma teatral y del tema. A condición, claro está, que como en el escenario isabelino los papeles femeninos estén desempeñados por hombres. Todo es allí real e irreal, falso y verdadero. Ya no sabríamos decir de qué lado del espejo nos encontramos: como si todo fuera un reflejo (Kot 1989: 320-321) y, mediante ese juego, puede destacarse el tema de la imposibilidad de elección entre el muchacho y la mujer, la universalidad del deseo imposible de detener y limitar a un solo sexo, la frágil frontera entre la amistad y el amor, la fascinación por toda belleza (Kot 1989:289).

El encanto de Rosalinda (Como gustéis) y Viola (Noche de Reyes) es irresistible. Seduce a todos, a los hombres como muchacha, a las mujeres como muchacho. Es una androginia casi perfecta. (Kot 1989: 302). Pero ambas son un actor disfrazado. Van borrándose lentamente las fronteras entre la ilusión y la realidad, entre el objeto y su reflejo (Kot 1989: 320) y las escenas amorosas tienen una lógica del sueño: se mezclan y se superponen en ellas los planos, los personajes y los tiempos, la parodia y la poesía. (Kot 1989: 322).

En Como Gustéis Rosalinda, disfrazada de muchacho, encuentra en el Bosque de Arden a Orlando. Orlando está enamorado de ella y ella lo está de él. Pero Orlando no reconoce a Rosalinda en su disfraz de Ganímedes, y acepta que este actúe para él interpretando a su amada. Rosalinda seduce a Orlando de manera bastante osada, pero lo hace como un muchacho que quiere en esta unión ser mujer para su hombre (Kot, 319). El compañero es corporal y a la vez fruto de la imaginación, transformado por el deseo (Kot 1989: 290). El amor es una huida de la cruel historia a un imaginario bosque. El Bosque de Arden es el lugar de concurrencia de todos los sueños, de conciliación de todas las contradicciones. En aquel Bosque, el amor es terrestre y sublimado a la manera platónica; Rosalinda es Ganímedes y, al mismo tiempo, la más femenina de las mujeres; Encarna la misma nostalgia del paraíso perdido que carecía de división de elementos masculino y femenino (Kot 1989: 346-347). En las escenas finales se entremezclan los cuerpos de muchachos y muchachas, el deseo y el amor $y$, en consecuencia, se percibe el 


\section{perifèria}

Número 20 (2), diciembre 2015

revistes.uab.cat/periferia

doble sentido del juego de disfraces: espiritual y físico, intelectual y sensual (Kot 1989: 324).

Desde los primeros versos, todo en Noche de Reyes es ambiguo. La intriga no es más que un pretexto; el tema es un juego de disfraces amoroso (Kot 1989:304). Iliria es el país del delirio del amor y las metamorfosis del sexo (Kot 1989: 310).

Tres personajes agotan todas las formas del amor. Olivia ama a Cesario, Cesario ama al Duque, el Duque ama a Olivia. Pero Cesario es Viola disfrazada. La androginia shakespeariana se convierte en masculina para Olivia y en femenina para el Duque. $Y$ ya tenemos una tercera mutación del mismo triángulo: ambos, Olivia y el Duque, están enamorados de un actor muchacho-muchacha. Finalmente, todo se resuelve con la aparición del hermano gemelo de Viola, Sebastián. Olivia toma en matrimonio al gemelo Sebastián y Viola revela su amor por el Duque, que acepta casarse con ella. La amistad se transforma en amor. El amor en amistad. En definitiva, ¿Que era la apariencia en esta comedia de confusiones? El amor y el deseo pasan de un muchacho a una muchacha y de una muchacha a un muchacho (Kot 1989: 312-313). ¿Quién fue engañado aquí? ¿Quién se dejó llevar por las apariencias? ¿Pertenece el deseo al orden de la naturaleza o al del amor? El amor es loco. ¿Y la naturaleza? ¿Puede la naturaleza ser loca e irracional? (Kot 1989: 311).

\section{La actriz de varones}

\section{Siglo de Oro español}

En 1587, la compañía italiana I Confidenti se encontró en Madrid con la prohibición general de que las mujeres pisaran el escenario. Protestaron alegando que las comedias que traían para representar no podían hacerse sin las mujeres de la compañía y por ello, -argumento definitivo-, los hospitales municipales perderían la limosna asignada. (El carácter benéfico de las representaciones teatrales a favor de los hospitales municipales es una de las características relevantes para entender el fenómeno teatral de esa época). La propuesta tuvo éxito y la brecha abierta fue aprovechada por las compañías españolas. Diez años más tarde se intentó 


\section{perifèria}

\section{Número 20 (2), diciembre 2015 \\ revistes.uab.cat/periferia}

nuevamente prohibir las representaciones con actrices, pero los Reglamentos de 1608, 1615 y 1641 dejan constancia de que tal prohibición no surtió efecto y de que la participación de las mujeres en las representaciones se había convertido en algo habitual (Oehrlein 1993: 221-224).

Hasta entonces los papeles femeninos habían sido representados por niños. Esta solución era efectivamente sostenible desde un punto de vista moral, si bien se consideraba insuficiente: "aunque esto de representar muchachos, vestidos de muger, de buen parecer, y acicalados, lo tenían algunos por mayor inconveniente" (Oehrlein 1993: 220). La entrada de mujeres en escena prohibió, en algunos casos, esta práctica y provocó que la nueva hubiera de ser reglamentada. La primera condición era que las mujeres debían estar casadas y tener a sus esposos consigo (Oehrlein 1993: 222).

Era este un matrimonio de conveniencia, en el que no eran infrecuentes los adulterios, concubinatos e incluso, bigamias. Podríamos pensar que ello podría tener su origen en el carácter utilitario con que fue contraído, unido a la supuesta laxitud moral de los actores y actrices. Sin embargo, no era una característica específica de los matrimonios entre actores: la Inquisición, a partir de 1566, procesó infinidad de casos por alegar que no era pecado acostarse con una mujer fuera del matrimonio y entre 1540 y 1700 se darían 264 casos de bigamia en el tribunal inquisitorial de Logroño, 243 en Toledo, 248 en Galicia, 190 en Sevilla y 162 en Zaragoza. (García Cárcel 1985: 24). No obstante, el celo represivo de inquisidores, moralistas y gobernantes no consiguió eliminar completamente las arraigadas costumbres.

La segunda condición a que estaba sujeta la autorización para que las mujeres pudieran representar era que debían llevar ropas femeninas. Los Reglamentos de 1608, 1615 y 1641 así lo disponen, aunque las infracciones no cesaran de producirse. Es más, la suspensión de la prohibición general de representaciones teatrales en la segunda mitad de los años cuarenta se dio a condición de que se mantuviesen las normas morales del vestido de los actores en el escenario y en un decreto real del 1 de enero de 1653, en cuanto a las mujeres varoniles se dice: "que ninguna mujer pueda salir al teatro en hábito de hombre, y 


\section{perifèria}

\section{Número 20 (2), diciembre 2015}

revistes.uab.cat/periferia

que si huviese de ser preciso para la representación, que hagan esto papeles, sea con traje tan ajustado y modesto, que de ninguna manera se les descubran las piernas ni los pies, sino que esto esté siempre cubierto con los vestidos ó trajes que ordinariamente usan, ó con alguna sotana, de manera que sólo se diferenzie el traje de la cintura arriba" (Oehrlein,1993: 163).

En numerosas obras la mujer con atuendo masculino era parte integrante de la acción. Es un fenómeno no suficientemente estudiado y en los pocos casos en que se ha hecho, ha sido bajo una misma perspectiva, la de su atractivo erótico El análisis de Melveena McKendrick Woman and Society in the Spanish Drama of Golden Age. A Study of the mujer varonil, interpreta la cuestión: "Nowhere but in the theatre could a man publicly enjoy the sight of the female leg clearly outlined from the ankle to thigh. This was enough to prompt churchman and moralist to agitate for laws forbidding the use of male clothing by actresses" (Oehrlein 1993: 226). Asimismo, J. Oehrlein en el capítulo dedicado a la mujer varonil, afirma: "el más alto grado de estimulación erótica para el público durante esta época venía dado por la aparición en escena de mujeres que imitaban los ademanes masculinos" (Oehrlein, 225), después de haber citado las palabras de Diez Borque: "(la actriz) pienso que en gran medida fue responsable del éxito masivo de la comedia, pues nunca hay que olvidar el factor erótico como elemento de atracción al espectáculo" (Oehrlein 1993: 224).

Oehrlein, incluso, al analizar la obra de Luis Vélez de Guevara "La Baltasara", (en ella una bella mujer experimentada en el desempeño de papeles de mujer con atuendo masculino al final de la obra se transforma en santa anacoreta) concluye que una mujer de vida poco ejemplar, que representa un tipo de mujer, desde el punto de vista del guardián de la moral, más que despreciable, si sufre semejante transformación de su pensar y obrar debe responder a alguna motivación económica, pues era un hecho frecuente retirarse de la escena para recluirse en un convento, y repetidamente ello ocurría después de morir el marido, al ser desposeída del derecho a seguir actuando (Oehrlein 1993: 227-230).

No obstante, podría analizarse "la Baltasara" desde otro ángulo ya que el aspecto de trasgresión de las fronteras entre los géneros parece no haber sido 


\section{perifèria}

Número 20 (2), diciembre 2015

revistes.uab.cat/periferia

tomado en consideración en ningún trabajo, por más que haya apuntes, en los comentarios de la época y en los de J. Oehrlein, que podrían conducir a ello. Así, de la actriz Bárbara Coronel se dice en la época: "muger casi hombre, y la amazona de las farsantas de su tiempo, que mal hallada con la debilidad de su sexo" (Oehrlein 1993: 225) y de la Baltasara: "era la Baltasara primera dama, y no solo desempeñaba este papel con perfección, sino que era muy aplaudida en la execución de otros papeles, en que vestida de hombre hacía de valiente, montando á caballo, haciendo guapezas, y intimando retos y desafíos" (Oehrlein 1993: 227).

Es más, esta transgresión puede percibirse en la discusión que en toda esa época se mantuvo acerca de la "licitud" de las representaciones, Fray José acusaba a las actrices que llevaban trajes del otro sexo de violación del orden natural querido por Dios, citando a este respecto el Deuteronomio "No se vista la mujer vestido de hombres, ni el hombre vestidura de mujer, porque lo uno y lo otro es abominable cerca de Dios" (Oehrlein, 210).

El mismo Oehrlein refiriéndose a Bodini destaca: "al levantarse el telón el espectador sufre un choc al verla vestida de hombre, lo que indudablemente representa una ruptura de la norma" (Oehrlein 1993: 227). Y también cita de McKendrick, para explicar la fascinación que su figura ejercía en las mujeres, "For the woman theatre-goers the mujer varonil provided the pleasure of vivacious freedom and adventure" (Oehrlein 1993: 226).

Y asimismo, me atrevo a conjeturar, proporcionaba al público espectador un vivificante placer de libertad y aventura.

\section{A modo de conclusión}

El actor y la actriz construyen identidades; pueden representar a alguien del otro sexo. Los actores y actrices, a través de su cuerpo ficticio y del modelado de la energía, pueden representar indistintamente personajes femeninos o masculinos mediante delimitadas técnicas extra-cotidianas (inculturadas o aculturadas). El resultado dependerá de su talento y capacidad. 


\section{perifèria}

Número 20 (2), diciembre 2015

revistes.uab.cat/periferia

El cuerpo es una ficción social y existe una naturalización sexuada de las cualidades personales y las emociones. La metáfora teatral puede encarnarse en la vida social. Si nos alejamos de las dos únicas categorías genéricas, se abren múltiples posibilidades de reconfiguración del imaginario cultural. Mirando al futuro: ¿Existiría alguna forma específica de ser mujer u hombre pues, como dijera Baudrillard: "Todos somos simbólicamente transexuales" (G. Cortés 1997: 89).

\section{Bibliografía}

Barba, Eugenio y Savarese Nicola (1990). El Arte Secreto del Actor, México, Edt. Escenología AC

Bregazzi, Josephine (1999). Shakespeare y el teatro renacentista inglés, Madrid, Alianza editorial

García Cortés, José Miguel (1997). El rostro velado. Travestismo e identidad en el arte, Donostia, Diputación Foral de Guipúzcoa

Heilbrun, Carolyn G. (1982). Toward a recognition of androgyny, New York, W.W. Norton \& Company, Inc.

Herdt, Gilbert (Edt.) (1993). Third Sex. Third Gender. Beyond Sexual Dimorphism in Culture and History, NewYork, Zone Books. DOI: $10.2307 / 483350$

Kot, Jan (1989). Apuntes sobre Shakespeare, Barcelona, Seix Barral.

Laqueur, Thomas (1990). La construcción del sexo. Cuerpo y género desde los griegos hasta Freud, Madrid, Cátedra.

Oehrlein, Josef (1993). El actor en el teatro del Siglo de Oro, Madrid, Castalia.

García Cárcel, Ricardo (1985). "La vida en el siglo de Oro", Cuadernos historia 16, no 129. 


\section{perifèria}

Número 20 (2), diciembre 2015

revistes.uab.cat/periferia

Shakespeare, William (1991). Como gustéis, Madrid, Espasa Calpe.

Shakespeare, William (1991). Noche de Reyes, Madrid, Cátedra. 